\title{
Hypertrophic cardiomyopathy: New approaches and a time to reappraise older approaches
} \author{
Jonathan N. Ginns, MD \\ From the Departments of ${ }^{\mathrm{a}}$ Surgery, ${ }^{\mathrm{b}}$ Pediatrics, and ${ }^{\mathrm{c}}$ Medicine, Columbia University Medical Center, New York, \\ NY. \\ Disclosures: Authors have nothing to disclose with regard to commercial support. \\ Received for publication April 8, 2016; revisions received May 18, 2016; accepted for publication June 17, 2016; \\ available ahead of print July 26, 2016. \\ Address for reprints: Hiroo Takayama, MD, PhD, 177 Fort Washington Ave, New York, NY 10032 (E-mail: \\ hirofu2@hotmail.com). \\ J Thorac Cardiovasc Surg 2016;152:983-8 \\ $0022-5223 / \$ 36.00$ \\ Copyright $(2) 2016$ by The American Association for Thoracic Surgery \\ http://dx.doi.org/10.1016/j.jtcvs.2016.06.034
}

Hiroo Takayama, MD, PhD, ${ }^{\text {a }}$ Wendy K. Chung, $\mathrm{MD}, \mathrm{PhD},{ }^{\mathrm{b}}$ Mathew S. Maurer, $\mathrm{MD},{ }^{\mathrm{c}}$ and
In a recent issue of Science, Green and colleagues described the successful application of a novel therapy for a mouse model of hypertrophic cardiomyopathy (HCM) with a mutant overactive form of the cardiac myosin heavy chain, the most common mutation affecting humans with this disorder. Their team designed a small-molecule (MYK-461) inhibitor of the abnormal protein that reduced excess sarcomere power output and thus successfully prevented the development of ventricular hypertrophy, cardiomyocyte disarray, and myocardial fibrosis. This important innovation sheds light on the unique pathophysiology of this disorder and may form the basis of treatment trials in humans, and it is therefore important to bring to the attention of the surgical community. We discuss the possible application of this therapy and use this as an opportunity to review the important surgical approaches to this disease and the competing procedures used by the interventional cardiology community.

\section{MYK-461 AS A CURE FOR HCM?}

It is well-established that patients with HCM tend to have hyperdynamic systolic function. It is known that this hypercontractility precedes the development of left ventricular hypertrophy $(\mathrm{LVH}){ }^{2,3}$ Previous studies have shown that this hypercontractility is caused by mutant myosin proteins with enhanced ATPase activity, increased tension development, and/or increased unloaded actin-filament sliding velocities. ${ }^{4}$ It is hypothesized that this hyperfunctioning protein, instead of being a beneficial mutation, leads to the development of hypertrophy, myocyte disarray, and fibrosis. This finding leads to the hypothesis that inhibition of the activity of these overactive proteins could be beneficial in the treatment of HCM. Green and colleagues hypothesized that a small-molecule inhibitor of myosin, MYK-461, in individuals with the abnormal overactive form of this protein would prevent the development of the pathologic abnormalities of HCM. ${ }^{1}$ Using a

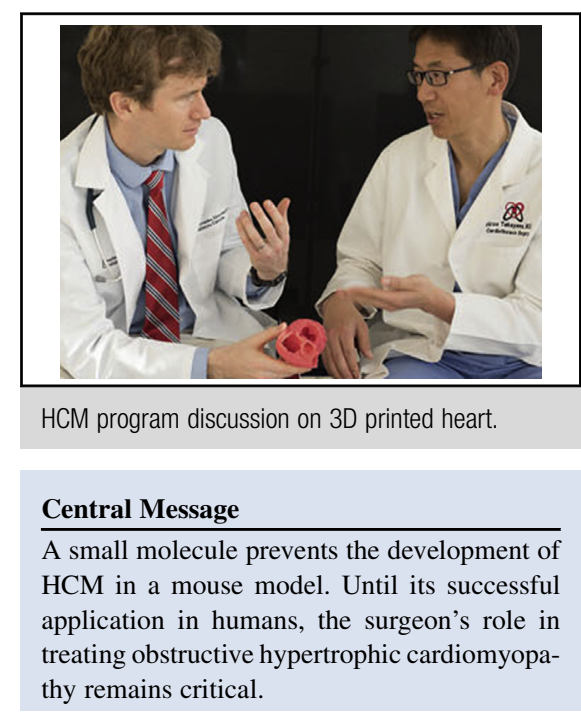

See Editorial Commentary page 988.

mouse model, in which human-disease-causing mutations were introduced into the murine $\alpha$-cardiac myosin heavy-chain gene, ${ }^{5,6}$ they have elegantly demonstrated that early, chronic administration of MYK-461 does prevent the development of ventricular hypertrophy, cardiomyocyte disarray, and myocardial fibrosis, and attenuates hypertrophic and profibrotic gene expression in HCM mice. In addition, MYK-461 therapy in older mice with overt LVH showed partial regression of myocardial hypertrophy (Figure 1). Of importance, skeletal muscle function (grip strength or voluntary exercise capacity) was not impaired even though MYK-461 also inhibits the ATPase activity of skeletal myosin. The potential clinical implications of the study by Green and colleagues are multifold. Drug administration before the development of the HCM phenotype may prevent the development of the disease in patients with mutations in sarcomere protein genes, including MYH7 and MYBPC3 (the 2 commonest types of mutations in humans). Late administration might halt disease progression or induce regression. This discovery could potentially signify the dawn of a new era of treatment, although clinical trials will need to be performed to demonstrate safety and efficacy in humans.

MYK-461 has been tested in phase I clinical trials. Successful cure of HCM with MYK-461, as well as any other targeted pharmacologic therapies, however, will face a number of challenges. Despite tremendous efforts, 




Young HCM patient

Genetic predisposition but no pathology yet

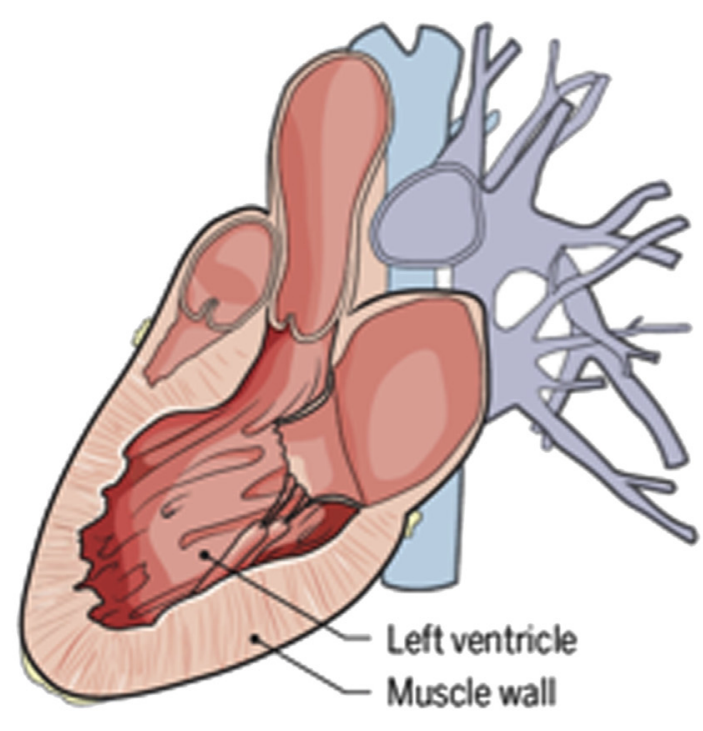

Myosin inhibitor treatment

No disease

Hyperdynamic muscle contraction not occurring

Discontinue treatment

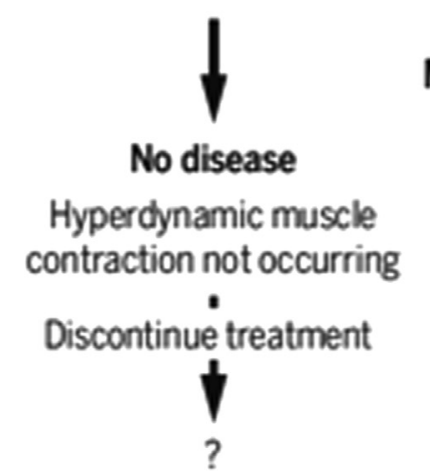

?

\section{Older HCM patient}

Genetic predisposition and pathology seen

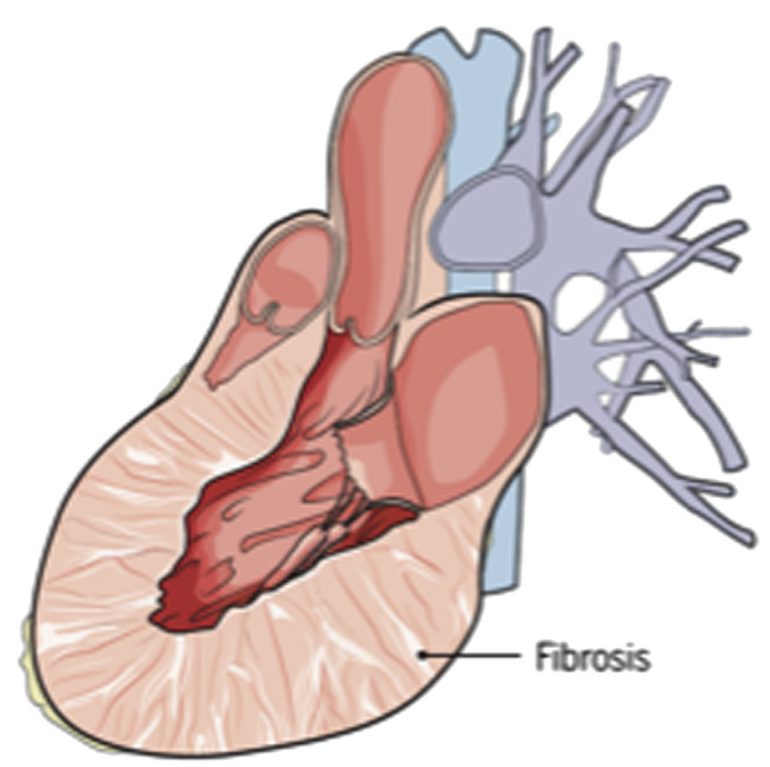

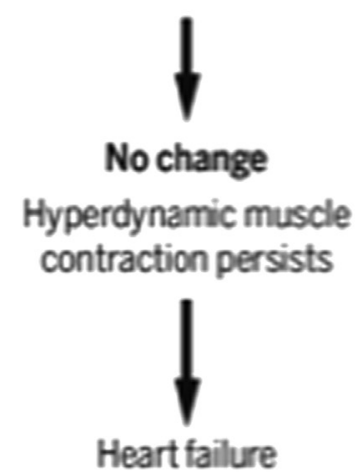

FIGURE 1. Mutations in myosin that increase power generation lead to hypertrophic cardiomyopathy (HCM). In a mouse model of HCM, early intervention with a small-molecule inhibitor of myosin reverses the disease (hypothetical patient scenario is shown). Such intervention could simplify treatment and become a generalized approach to control many contractile protein mutations that lead to HCM, or the use of myosin activators for dilated cardiomyopathy. (Adapted with permission from Warshaw, ${ }^{7}$ Copyright $(C)$ The American Association for the Advancement of Science.)

pharmaceutical innovations at the patient level are becoming rare events. ${ }^{8}$ From 1991 to 2000 , only $11 \%$ of all drugs tested in phase I trials were eventually successfully registered. ${ }^{9}$ In addition to the obvious uncertainties with regard to the clinical effects and potential toxicities, successful application of MYK-461 will likely require 
identification of $\mathrm{HCM}$ patients before their clinical presentation.

\section{UPDATES ON MANAGEMENT OF OBSTRUCTIVE HCM}

The development of a novel therapy for HCM should cause us to reflect on the current state of medical and surgical management of this disease. In particular, the desire for curative treatment highlights the degree of disability caused by this most common cardiac disorder. Notably, a recent study suggests that HCM may affect up to 1 in 200 adults $^{10}$ and more than $60 \%$ of patients in whom left ventricular outflow tract (LVOT) obstruction develops. Medical therapy for HCM through the use of $\beta$-blockers, calcium channel blockers, and disopyramide are only partially successful and may have significant side effects, but they should remain the first-line therapy. If these numbers are simply put together, a large number of patients may potentially benefit from septal reduction therapy. Surgical myectomy has been considered the gold standard for the treatment of severe, medically refractory symptoms resulting from $\mathrm{LV}$ outflow tract obstruction, and it is clearly stated as such in the American College of Cardiology/ American Heart Association guidelines. ${ }^{11}$ Despite the large number of patients with this disorder, and the fact that over $60 \%$ to $70 \%$ of them have some degree of obstruction, only a small number of septal myectomies for relief of HCM are performed each year. This is the case even though it is the best recommended of the modern therapies used at experienced centers and has been shown to be able to reduce mortality rates in this disorder to those of the normal population. It seems likely there is a vast unmet need for septal myectomy.

Septal myectomy has evolved and become highly refined. Although a detailed description of the procedure is beyond the scope of this article, several surgical details are highlighted here. It is of fundamental importance to perform "extended" septal myectomy (deeper toward the apex and wider toward the mitral valve), whereas early reports of Morrow $^{12}$ described narrower muscle resection. The technique is championed by the Mayo group and their technical details are described elsewhere with excellent illustrations (Figure 2). ${ }^{13}$ Achieving adequate resection of the length, width, and thickness of the hypertrophic interventricular septum is paramount to the success of the procedure. The judgment of the appropriateness of myectomy relies on the surgeon's subjective assessment through the limited transaortic surgical field. Marwick and colleagues $^{14}$ reported that up to $20 \%$ of patients were placed back on cardiopulmonary bypass because of inadequate resection based on these post-bypass objective studies. Furthermore, the most common mechanisms of recurrence appeared to be inadequate resection at the initial myectomy, mostly in depth or width or both. ${ }^{15,16}$ We have been using a bimanual septal palpation technique, which allows better appreciation of the extent of the resection. ${ }^{17}$ Retrospective analysis suggests that relief of LVOT obstruction with septal myectomy may improve survival of patients with obstructive HCM. The contemporary extended septal myectomy abolishes or substantially reduces LV outflow tract gradients in over $90 \%$ of cases, reduces systolic anterior motion-related mitral regurgitation, and improves exercise capacity and symptoms. Of importance, the surgery can be performed with an operative mortality rate of less than $0.5 \%{ }^{18}$ There has been no mortality in the 40 consecutive isolated septal myectomies performed since the development of our HCM center in 2011.

A rare subset of patients with HCM, typically with nonobstructive disease, develop heart failure symptoms refractory and/or nonamenable to medical or invasive therapy and require heart transplantation ${ }^{19}$; the posttransplant outcome of patients with HCM is superior to other cohorts. $^{20}$ Transapical septal myectomy and/or apical myectomy have recently been advocated as a new therapy for apical and midventricular HCM, and this may provide sufficient symptomatic relief and avoidance of heart transplantation. ${ }^{21,22}$

Several new adjunctive procedures have been advocated predominantly as interventions on the mitral valve and its subvalvular apparatus, such as division of the attachment between the papillary muscle and the septum, resection of additional muscle around the base of the papillary muscles, ${ }^{23}$ anterior leaflet plication, ${ }^{24}$ papillary muscle reorientation, ${ }^{25}$ and cutting thickened secondary chords. ${ }^{26}$ Mitral valve replacement in the absence of organic mitral diseases, such as rheumatic valve disease or nonrepairable diseases, is not necessary for this entity and should be discouraged.

A catheter-based procedure, alcohol septal ablation (ASA), has recently been popularized as a less-invasive alternative to surgical therapy. This procedure, first introduced in 1994, involves injection of 1 to $4 \mathrm{~mL}$ of $96 \%$ ethanol into the first septal branch of the left anterior descending coronary artery to produce a basal septal myocardial infarction in order to reduce the LVOT muscle mass. The benefits of ASA and septal myectomy are compared in Table 1. Currently, ASA is not regarded as the primary treatment option for such patients with a similar severity of functional limitation, but rather as a useful, selective alternative to septal myectomy for patients of advanced age, patients at high operative risk as a result of important comorbidities, or those with a strong personal preference to avoid surgery. A recent systemic review/ meta-analysis best compares the long-term outcomes of these 2 invasive septal reduction therapies, and their key findings are incorporated in Table $1 .{ }^{27}$ In this analysis, only studies with a follow-up of at least 3 years were included with 16 myectomy cohorts $(\mathrm{n}=2791$; mean 




FIGURE 2. Two operative approaches for performing septal myectomy in obstructive HCM. A (right insert), Typical outflow tract morphology with predominant basal septal hypertrophy and subaortic obstruction caused primarily by systolic anterior motion of the mitral valve. Endocardial thickening at the line of apposition of the anterior mitral leaflet to the septum (friction lesion) can be seen. A (left insert), A standard rectangular myectomy trough (Morrow procedure) is created from $1 \mathrm{~cm}$ below the aortic valve apically to a point beyond the line of the mitral-septal contact and intraventricular obstruction, allowing relief of the outflow tract gradient and preservation of the sinus rhythm. B, In the presence of a muscular midcavity obstruction caused by anomalous papillary muscles with direct insertion into the mitral valve or by extensive diffuse septal hypertrophy extending to the bases of the papillary muscles, a much more substantial myectomy is performed by combining the standard operation with an extended midventricular resection. The apical portion of the myectomy trough is much wider and includes the distal third of the right side of the septum. (Adapted with permission from Dearani et al, ${ }^{13}$ Copyright $\subset$ Nature Publishing Group.)

follow-up, 7.4 years) and 11 ASA cohorts $(\mathrm{n}=2013$; mean follow-up, 6.2 years). Although long-term mortality (septal myectomy $1.4 \%$ per year vs ASA $1.5 \%$ per year, $P=.78$ ) and the rate of (aborted) sudden cardiac death, including appropriate implantable cardioverter defibrillator shocks (septal myectomy $0.5 \%$ per year vs ASA $0.4 \%$ per year, $P=.47)$ were comparable, permanent pacemaker implantation and reintervention were less frequent after septal myectomy $(4.4 \%$ after septal myectomy vs $10 \%$ after ASA, $P<.001 ; 1.6 \%$ vs $7.7 \%, P=.001$, respectively). The previous notion on a possibly higher incidence of ASA-induced ventricular arrhythmia was not observed. Importantly, periprocedural mortality was higher after septal myectomy at $2.5 \%(1.3 \%$ after ASA, $P=.051)$; however, when septal myectomy studies from before 2000 were excluded, the periprocedural mortality rate became equivalent $(1.1 \%$ after septal myectomy vs $1.3 \%$ after ASA, $P=.75$ ). The mortality after isolated septal myectomy was likely lower given several of these studies included patients who had undergone concomitant nonmitral cardiac procedures such as coronary bypass and aortic valve replacement. Periprocedural rates of pacemaker implantation $(4.0 \%$ after septal myectomy vs $10.0 \%$ after ASA, $P<.001)$ and adverse arrhythmic events $(0.6 \%$ vs $2.2 \%$ after ASA, $P=.055)$ were lower after septal myectomy.

The number of ASA procedures now far outnumber the number of septal myectomy operations performed overall in any given year. ${ }^{28}$ It has been estimated that the total number of ASAs in the last 10 years exceeds by a large margin all septal myectomy operations performed in almost 50 years. The low penetration of the septal myectomy procedure is likely due to a variety of reasons. The small number of procedures performed by an individual surgeon may lead to less than ideal outcomes; it is a complex operation and, if outcomes are not perfect, cardiologists will not refer. Patients are reluctant to undergo surgery when a less-invasive option is presented, especially when that procedure is performed by those who need to refer the patients for surgery, and no good head-to-head comparisons of both procedures have been performed in a randomized fashion (like the transcatheter aortic valve 
TABLE 1. Comparison of extended septal myectomy and alcohol septal ablation: Anatomic/clinical considerations and results of a meta-analysis

\begin{tabular}{|c|c|c|c|c|c|}
\hline & \multicolumn{2}{|c|}{ Extended septal myectomy } & \multicolumn{3}{|c|}{ Alcohol septal ablation } \\
\hline $\begin{array}{l}\text { Anatomic } \\
\text { advantages }\end{array}$ & $\begin{array}{l}\text { Immediate rel } \\
\text { (vs several } \\
\text { Can address e } \\
\text { septum } \\
\text { No relevance } \\
\text { anatomy (A } \\
\text { appropriate } \\
\text { Ability to add } \\
\text { anomalies } \\
\text { Ability to add } \\
\text { other cardia } \\
\text { necessary }\end{array}$ & $\begin{array}{l}\text { of obstruction } \\
\text { eks for ASA) } \\
\text { emely thick } \\
\text { coronary } \\
\text { requires } \\
\text { ptal perforator) } \\
\text { s mitral } \\
\text { s concomitant } \\
\text { esions if }\end{array}$ & & & \\
\hline \multirow[t]{2}{*}{$\begin{array}{l}\text { Clinical } \\
\text { advantages }\end{array}$} & \multicolumn{2}{|c|}{$\begin{array}{l}\text { Proven long-term efficacy } \\
\text { Less need for PPM, repeat } \\
\text { invasive therapy } \\
\text { No myocardial scar } \\
\text { Applicable to children and } \\
\text { young adults }\end{array}$} & \multicolumn{3}{|c|}{$\begin{array}{l}\text { Proven short-term } \\
\text { efficacy } \\
\text { Shorter hospital stay } \\
\text { and faster recovery } \\
\text { No cutaneous scar } \\
\text { Less invasive. Better } \\
\text { tolerated by surgically } \\
\text { high risk patients } \\
\text { Less discomfort }\end{array}$} \\
\hline & \multicolumn{2}{|c|}{ Meta-analysis $^{27}$} & & & \\
\hline \multicolumn{2}{|c|}{$n$} & 2791 & & 2013 & $\boldsymbol{P}$ \\
\hline \multicolumn{6}{|c|}{ Periprocedural outcomes } \\
\hline \multicolumn{2}{|c|}{ Mortality $(\%)$} & \multicolumn{2}{|c|}{$\begin{array}{l}2.5(1.1 \% \text { for studies } \\
\text { after } 2001)\end{array}$} & 1.3 & .75 \\
\hline \multicolumn{2}{|l|}{ PPM (\%) } & 4.4 & & 10 & $<.001$ \\
\hline \multicolumn{2}{|c|}{ Tamponade $(\%)$} & 1 & & 0.6 & .5 \\
\hline \multicolumn{2}{|l|}{ Stroke $(\%)$} & 0.9 & & 0.3 & .15 \\
\hline \multicolumn{2}{|c|}{$\begin{array}{l}\text { Total adverse arrhythmic } \\
\text { event }(\%)\end{array}$} & 1 & & 2.2 & .055 \\
\hline \multicolumn{6}{|c|}{ Long-term outcomes } \\
\hline \multicolumn{2}{|c|}{ Mortality $(\% / y)$} & 1.44 & & 1.52 & .78 \\
\hline \multicolumn{2}{|c|}{ (Aborted) SCD $(\% / y)$} & 0.49 & & 0.41 & .47 \\
\hline \multicolumn{2}{|c|}{$\begin{array}{c}\text { Median reduction of } \\
\text { NYHA class }(\%)\end{array}$} & 45 & & 45 & .94 \\
\hline \multicolumn{2}{|c|}{$\begin{array}{l}\text { Reduction in LVOT } \\
\text { gradient }(\%)\end{array}$} & 77 & & 71 & .63 \\
\hline \multicolumn{2}{|c|}{ No. of reintervention $(\%)$} & 1.6 & & 7.7 & .001 \\
\hline
\end{tabular}

ASA, Alcohol septal ablation; PPM, permanent pacemaker; $S C D$, sudden cardiac death; NYHA, New York Heart Association; LVOT, left ventricular outflow tract.

replacement trials). With lack of good data, clinical equipoise can remain. Individualized clinical decision making is necessary, and it is best guided by the multidisciplinary comprehensive HCM Heart Team.

The current situation might reflect the lack of "attention" by our specialty. Every guideline or review on septal reduction therapy emphasizes the importance of surgical expertise in order to appropriately perform septal myectomy, as well as the scarcity of surgical experts. Our professional society should recognize the fact that septal myectomy is one of the remaining few cardiac surgical procedures in the contemporary era that is considered the best recommended therapy in the guidelines, and it is our responsibility to maintain and develop proper surgical education as well as to enhance surgeons' interest and advance surgical science in this entity in order to better serve our patients.

\section{References}

1. Green EM, Wakimoto H, Anderson RL, Evanchik MJ, Gorham JM, Harrison BC, et al. A small-molecule inhibitor of sarcomere contractility suppresses hypertrophic cardiomyopathy in mice. Science. 2016;351:617-21.

2. Ho CY, Sweitzer NK, McDonough B, Maron BJ, Casey SA, Seidman JG, et al. Assessment of diastolic function with Doppler tissue imaging to predict genotype in preclinical hypertrophic cardiomyopathy. Circulation. 2002;105:2992-7.

3. Forsey J, Benson L, Rozenblyum E, Friedberg MK, Mertens L. Early changes in apical rotation in genotype positive children with hypertrophic cardiomyopathy mutations without hypertrophic changes on two-dimensional imaging. J Am Soc Echocardiogr. 2014;27:215-21.

4. Moore JR, Leinwand L, Warshaw DM. Understanding cardiomyopathy phenotypes based on the functional impact of mutations in the myosin motor. Circ Res. 2012;111:375-85.

5. Geisterfer-Lowrance AA, Christe M, Conner DA, Ingwall JS, Schoen FJ, Seidman CE, et al. A mouse model of familial hypertrophic cardiomyopathy Science. 1996;272:731-4.

6. Georgakopoulos D, Christe ME, Giewat M, Seidman CM, Seidman JG, Kass DA The pathogenesis of familial hypertrophic cardiomyopathy: early and evolving effects from an alpha-cardiac myosin heavy chain missense mutation. Nat Med. 1999;5:327-30.

7. Warshaw DM. HEART DISEASE. Throttling back the heart's molecular motor Science. 2016;351:556-7.

8. Wehling M. Assessing the translatability of drug projects: what needs to be scored to predict success? Nat Rev Drug Discov. 2009;8:541-6.

9. Kola I, Landis J. Can the pharmaceutical industry reduce attrition rates? Nat Rev Drug Discov. 2004;3:711-5.

10. Semsarian C, Ingles J, Maron MS, Maron BJ. New perspectives on the prevalence of hypertrophic cardiomyopathy. J Am Coll Cardiol. 2015;65:1249-54.

11. American College of Cardiology Foundation/American Heart Association Task Force on Practice Guidelines, American Association for Thoracic Surgery, American Society of Echocardiography, Gersh BJ, Maron BJ, Bonow RO, et al. $2011 \mathrm{ACCF} / \mathrm{AHA}$ guideline for the diagnosis and treatment of hypertrophic cardiomyopathy: a report of the American College of Cardiology Foundation/ American Heart Association Task Force on Practice Guidelines. J Thorac Cardiovasc Surg. 2011;142:e153-203.

12. Morrow AG. Hypertrophic subaortic stenosis. Operative methods utilized to relieve left ventricular outflow obstruction. J Thorac Cardiovasc Surg. 1978;76:423-30.

13. Dearani JA, Ommen SR, Gersh BJ, Schaff HV, Danielson GK. Surgery insight: septal myectomy for obstructive hypertrophic cardiomyopathy-the Mayo Clinic experience. Nat Clin Pract Cardiovasc Med. 2007;4:503-12.

14. Marwick TH, Stewart WJ, Lever HM, Lytle BW, Rosenkranz ER, Duffy CI, et al Benefits of intraoperative echocardiography in the surgical management of hypertrophic cardiomyopathy. J Am Coll Cardiol. 1992;20:1066-72.

15. Minakata K, Dearani JA, Schaff HV, O'Leary PW, Ommen SR, Danielson GK Mechanisms for recurrent left ventricular outflow tract obstruction after septa myectomy for obstructive hypertrophic cardiomyopathy. Ann Thorac Surg. 2005;80:851-6.

16. Cho YH, Quintana E, Schaff HV, Nishimura RA, Dearani JA, Abel MD, et al Residual and recurrent gradients after septal myectomy for hypertrophic cardiomyopathy-mechanisms of obstruction and outcomes of reoperation. J Thorac Cardiovasc Surg. 2014;148:909-15; discussion 915-6.

17. Fukuhara S, Edwards S, Kurlansky P, Takayama H. Bimanual examination for septal myectomy for hypertrophic cardiomyopathy. Interact Cardiovasc Thorac Surg. 2014;19:735-7

18. Maron BJ, Dearani JA, Ommen SR, Maron MS, Schaff HV, Nishimura RA, et al Low operative mortality achieved with surgical septal myectomy: role of dedicated hypertrophic cardiomyopathy centers in the management of dynamic subaortic obstruction. J Am Coll Cardiol. 2015;66:1307-8.

19. Maron MS, Rowin EJ, Olivotto I, Casey SA, Arretini A, Tomberli B, et al Contemporary natural history and management of nonobstructive hypertrophic cardiomyopathy. J Am Coll Cardiol. 2016;67:1399-409. 
20. Kato TS, Takayama H, Yoshizawa S, Marboe C, Schulze PC, Farr M, et al. Cardiac transplantation in patients with hypertrophic cardiomyopathy. Am J Cardiol. 2012;110:568-74.

21. Said SM, Schaff HV, Abel MD, Dearani JA. Transapical approach for apical myectomy and relief of midventricular obstruction in hypertrophic cardiomyopathy. J Card Surg. 2012;27:443-8.

22. Schaff HV, Dearani JA, Ommen SR, Sorajja P, Nishimura RA. Expanding the indications for septal myectomy in patients with hypertrophic cardiomyopathy: results of operation in patients with latent obstruction. J Thorac Cardiovasc Surg. 2012;143:303-9.

23. Minakata K, Dearani JA, Nishimura RA, Maron BJ, Danielson GK. Extended septal myectomy for hypertrophic obstructive cardiomyopathy with anomalous mitral papillary muscles or chordae. J Thorac Cardiovasc Surg. 2004;127:481-9.

24. Swistel DG, Balaram SK. Surgical myectomy for hypertrophic cardiomyopathy in the 21 st century, the evolution of the "RPR" repair: resection, plication, and release. Prog Cardiovasc Dis. 2012;54:498-502.
25. Kwon DH, Smedira NG, Thamilarasan M, Lytle BW, Lever H, Desai MY Characteristics and surgical outcomes of symptomatic patients with hypertrophic cardiomyopathy with abnormal papillary muscle morphology undergoing papillary muscle reorientation. J Thorac Cardiovasc Surg. 2010;140: 317-24.

26. Ferrazzi P, Spirito P, Iacovoni A, Calabrese A, Migliorati K, Simon C, et al. Transaortic chordal cutting: mitral valve repair for obstructive hypertrophic cardiomyopathy with mild septal hypertrophy. J Am Coll Cardiol. 2015;66: 1687-96.

27. Liebregts M, Vriesendorp PA, Mahmoodi BK, Schinkel AF, Michels M, ten Berg JM. A systematic review and meta-analysis of long-term outcomes after septal reduction therapy in patients with hypertrophic cardiomyopathy. JACC Heart Fail. 2015;3:896-905.

28. Maron BJ, Nishimura RA. Surgical septal myectomy versus alcohol septal ablation: assessing the status of the controversy in 2014. Circulation. 2014; 130:1617-24.

\section{EDITORIAL COMMENTARY}

\section{Treating obstructive hypertrophic cardiomyopathy-what's best, what's next?}

\author{
Joseph A. Dearani, MD, ${ }^{a}$ and Michael J. Ackerman, $\mathrm{MD}, \mathrm{PhD}^{\mathrm{b}}$ \\ From the Departments of ${ }^{\mathrm{a} C}$ Cardiovascular Surgery and ${ }^{\mathrm{b}}$ Cardiovascular Diseases and Pediatric Cardiology, \\ Molecular Pharmacology and Experimental Therapeutics, Mayo Clinic, Rochester, Minn. \\ Disclosures: M.A. is a consultant for Boston Scientific, Gilead Sciences, Invitae, Medtronic, and St Jude Medical, \\ and has received royalties from Transgenomic. J.D. has nothing to disclose with regard to commercial support. \\ Received for publication July 26, 2016; accepted for publication July 29, 2016. \\ Address for reprints: Joseph A. Dearani, MD, Department of Cardiovascular Surgery and Cardiovascular \\ Diseases, Mayo Clinic, 200 First St SW, Rochester, MN 55905 (E-mail: jdearani@mayo.edu). \\ J Thorac Cardiovasc Surg 2016;152:988-90 \\ $0022-5223 / \$ 36.00$ \\ Copyright (c) 2016 by The American Association for Thoracic Surgery \\ http://dx.doi.org/10.1016/j.jtcvs.2016.07.051
}

Takayama and colleagues ${ }^{1}$ review current treatment strategies for patients with obstructive hypertrophic cardiomyopathy (HCM) and highlight a novel therapy (MYK-146) that decreases cardiac contractility and demonstrates exciting proof-of-principle in mouse models of HCM secondary to mutant cardiac beta myosin heavy chain. ${ }^{2}$ This innovation provides a potential platform for future treatment trials in humans affected with HCM.

Relief of left ventricular outflow tract obstruction in patients with HCM and symptomatic heart failure refractory to medical management has been historically surgical. Established centers performing extended septal myectomy have demonstrated early mortality of $<0.5 \%$, predictable symptoms, and late survival equivalent to the general population and superior to patients with obstructive HCM not undergoing operation. ${ }^{3}$

Nevertheless, alternatives to septal myectomy are necessary for selected patients with HCM. The current alternative is percutaneous alcohol septal ablation (ASA), which has

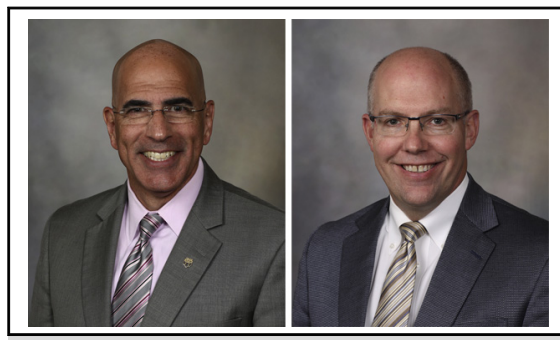

Joseph A. Dearani, MD, and Michael J. Ackerman, $\mathrm{MD}, \mathrm{PhD}$

\section{Central Message}

Septal reduction therapies will play an important role in the treatment of obstructive HCM. Septal myectomy is the optimal septal reduction therapy for patients at low risk for surgery.

See Article page 983.

garnered much enthusiasm from the interventional cardiology community because it achieves benefits by virtue of producing a transmural infarct. Although the indications for septal reduction therapy are the same for ASA and septal myectomy, the promotion of ASA has been excessive- the number of ASA procedures performed worldwide during the past decade $(>5000)$ has exceeded dramatically the number of myectomies performed during the past 50 years. Paradoxically, this heightened visibility of ASA for 